\title{
EXPERIMENTAL AND NUMERICAL INVESTIGATIONS FOR THE COMBUSTION OF SELECTED COMPOSITE SOLID PROPELLANT
}

\author{
Hegab $^{*}$, A.M., Hasanien ${ }^{\S}$, S.A., Mostafa ${ }^{\ddagger}$, H. E., Maraden ${ }^{* *}$, A.M \\ *Professor, Faculty of Engineering-Rabigh, King Abdulaziz University, KSA \\ ${ }^{\S}$ Maj. Gen. Assoc. Prof., former head of chemical Dept.,MTC \\ ${ }^{*}$ lt. Col. Dr., head of the explosive department, MTC \\ Captain Engineer, Military Technical College (MTC)
}

\begin{abstract}
In this study, numerical and experimental study for the packing and burning of composite solid propellant is presented. A mathematical model which describes the unsteady burning of a heterogeneous propellant by simultaneously solving the combustion fields in the gas phase and the thermal field in the solid phase with appropriate jump condition across the gas/solid interface is developed. The gas-phase kinetics is represented by a two-step reaction mechanism for the primary premixed flame and the primary diffusion flame between the decomposition products of the HTPB and the oxidizer AP. The propagation of the unsteady non-planer regression surface is described, using the Essentially-Non-Oscillatory (ENO) scheme with the aid of the level set strategy. Moreover, an experimental investigation for similar sample of 200 microns AP particles with 50 microns AP particles imbedded in a matrix of HTPB is performed. The results show that the large AP particle diameter has a great effect on the combustion surface deformation and on the burning rate as well. Moreover, the effect of various parameters on the surface propagation speed, flame structure, and the burning surface geometry is obtained.

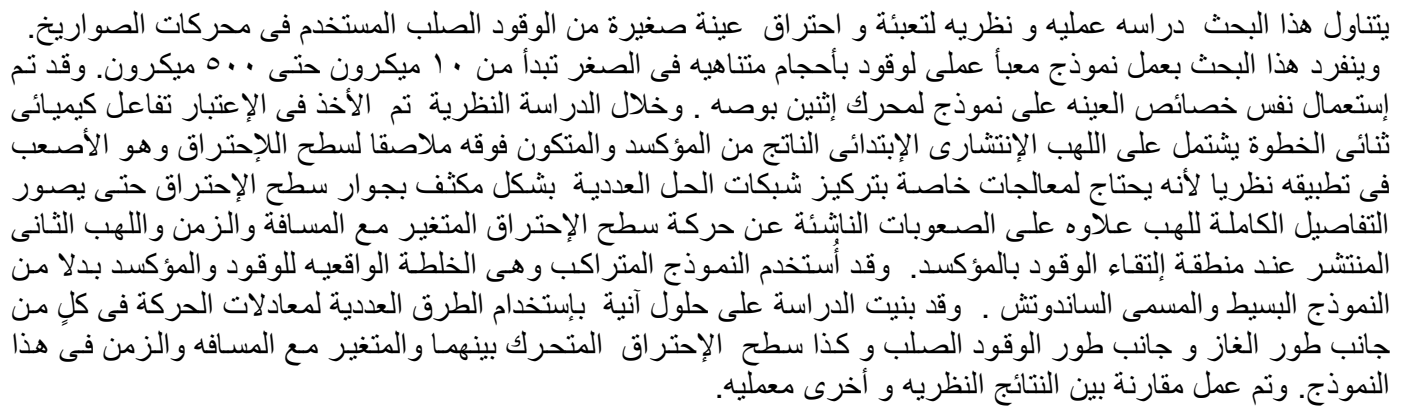

Keywords: Composite Propellant, Gas/solid Phases, Heterogeneous Propellant, AP/HTPB, Level Set Method.

\section{INTRODUCTION}

The ignition and combustion of composite energetic materials are considered the origin for the stability and performance of solid rocket motor engines. The packing and combustion of this kind of propellant are characterized by very high energy densities, extremely diverse length and time scales, complex interfaces, reactive, turbulent, and multiphase flows. These complexities are still a big challenge to perform the whole system simulation of solid rocket motor. Within the last three or four decades, many investigations have been conducted to acquire some information about the complex flame structure and the nature of the generated flow field inside the solid rocket motor chamber. Generally, the burning of the solid propellant of energetic materials, it is our believe, is the back-pone for the whole system simulation, since it is the deriving thermo-mechanical force in the operation of a solid rocket motor. 
Rocket propellants may be divided into two general classes, double-base propellants and composite propellants. The principle components of the double base propellants are nitrocellulose and an explosive plasticizer, usually nitroglycerin, [1-4], while the composite propellants are made by embedding a finely divided solid oxidizing agent in a binder. Regarding the latter composite propellant, oxidizing agents which have been used extensively include ammonium nitrate, sodium nitrate, potassium nitrate, ammonium perchlorate, and potassium perchlorate. The materials which have been employed as binders are, asphalt, natural and synthetic rubbers, vinyl polymers, polyesters, and nitrocellulose. Ammonium picrate, carbon black, and aluminum powder have been used as fuel fillers [5].

The current study has emphasized the composite propellants because they have been of greatest general interest over the modeling time period. The modern rocket composite propellant mixture consists of the following ingredients; an Ammonium Perchlorate (AP) (oxidizer, 69.6 percent by weight), aluminum (fuel, 16 percent), iron oxide (a catalyst, 0.4 percent), Hydroxyl Terminated Poly-Butadiance, (HTPB) fuel binder (a binder that holds the mixture together, 12.04 percent), and an epoxy curing agent (1.96 percent). AP, NH4ClO4, based composite propellants are widely used in a variety of rocket motor systems ranging from small tactical missiles to the large boosters that propel the space shuttle into orbit. The properties used for AP come from Beckstead et.al. [6, 7] and Guirao and Williams [8] and the JANNAF tables [3]. Most of the thermodynamic and transport properties used for HTPB come from the work of Parr and Hanson-Parr, adapted from Jeppson et.al. [9].

Theoretical and experimental studies of heterogeneous propellant combustion have a long history, much of it from the days when computational and experimental resources were primitive, which encouraged the development of grossly simplified models. Modeling of the combustion of a rocket composite propellant is more complex than that of a single component monopropellants.

To describe the complex gas phase flame structure, many assumptions about the components (fuel + oxidizer) in the system have been made. That is weather these components are mixed before combustion (premixed flame), or weather the two components must first diffuse together before the combustion can take place (diffusion flame). The following models have been adopted to furnish the baseline for the complex flame structure.

The basic idea for the burning of the rocket propellant is further illustrated in 1998 by Jeppson et.al. [6,9], as shown in Fig.1.

The composite solid propellant is at a given initial temperature. As the temperature increases, the AP portion of the propellant undergoes a partial decomposition. With further heating, the propellant ingredients can melt or liquefy and the condensed liquid layer forms. This condensed layer consists of many phases: solid to liquid AP, liquid HTPB, and gas phase bubbles. These bubbles contain the gaseous species formed by the semi-global condensed phase decomposition mechanism for liquid AP and HTPB. The temperature rises sharply as the gas phase flame develops in the third region "jump conditions".

Few decades ago, several theoretical studies on the combustion field of the burning of the heterogeneous propellant have been conducted. These researches are divided into two main categories. The first one is concentrated on the gas phase modeling without consideration for the condensed phase process. The second one is studied the condensed phase reaction as the most important factor, for example [10,11]. Recently, few studies [12, 13, 14] have been employed the complex coupling between the solidphase and gas-phase process, by solving the full Navier-Stokes in the gas-phase simultaneously with the energy one in the solid phase.

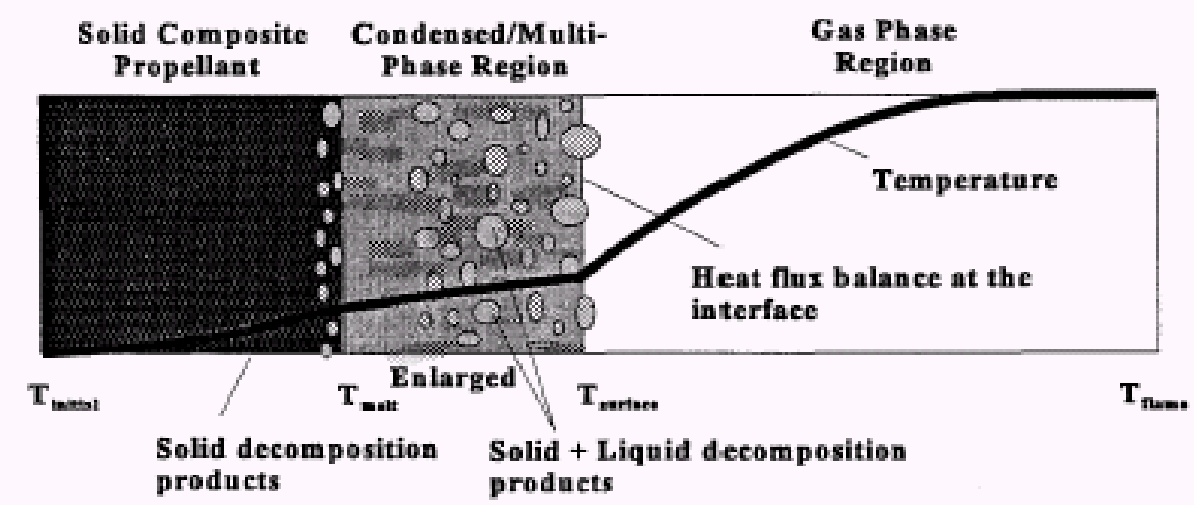

Fig. 1 Composite solid propellant combustion layers

\section{THE PHYSICAL MODELS}


It has long been recognized that the burning rate of the rocket propellant is influenced by the propellant morphology, by the size and size distribution of the ammonium perchlorate (AP) particles. In spite of, the sandwich models used as a convenient platform on which to generate the numerical code for the complex flame structure, but much serious attempt to simulate propellant burning numerically must incorporate a packing algorithm. In another word, a strategy for defining and constructing a model of packing rocket propellant numerically was required at that time. Fortunately, the packing algorithm is one that is of interest of several scientific fields and has been studied both experimentally and numerically.

McGeary, [15] reported a brief description of some experiments on the packing of steel shot. Bimodal packing was investigated in which spheres of diameter 0.124 in. are packed with smaller spheres. The packing volume is defined as the volume of the particles plus the interstitial volume. The packing fraction $\rho$ (the fraction of the packing volume that is particles) is measured as a function of the volume fraction of fine particles (the volume of fine particles divided by the total volume of particles); the results are reproduced in Fig. 2. When the particle volume fraction is 0 or $100 \%$, the packing is monomodal and the packing fraction is approximately 0.625. Higher packing fractions are achieved for bimodal packs and the greater the disparity in sizes, the greater the packing fraction. In all cases, the maximum occurs at approximately $30 \%$ fine, $70 \%$ coarse. The largest packing fraction is 0.8594 . A mathematical models for the 2D random packing strategies have developed by Kochevets, et.al. [16,17] , Knott, et.al. [18], and Buckmaster, et.al. [19,20] in order to numerically construct models of heterogeneous rocket propellants. Their packing algorithms are based on the integration of the random packing approach and the collision theory that has been described in a number of papers by Lubachevsky and his Colleagues in 1990,1991 [21] and by Zhang et.al. in 2001, [22]. These models deal with 2D combustion field supported by a disk pack propellant, in which full coupling between the gas phase, the condensed phase, and the retreating nonplanar propellant surface was accounted for. Recently, Hegab [23, 24, 25] describes a large number of periodic $2 \mathrm{D}$ disk pack models by assuming that the particles of the AP are 2D disks and distributing them in a random fashion and applied to monomodal, bimodal, and multimodal disc packs.

In this study, the physical domains are represented by two different models. The first one is the microscale propellant, $\mathrm{O}(1 \mathrm{~mm})$, following the same strategy by Hegab, et.al. [12,13,25] and the second model is the two-inch rocket motor used the same compositions in the microscale one as shown in Fig. 2.

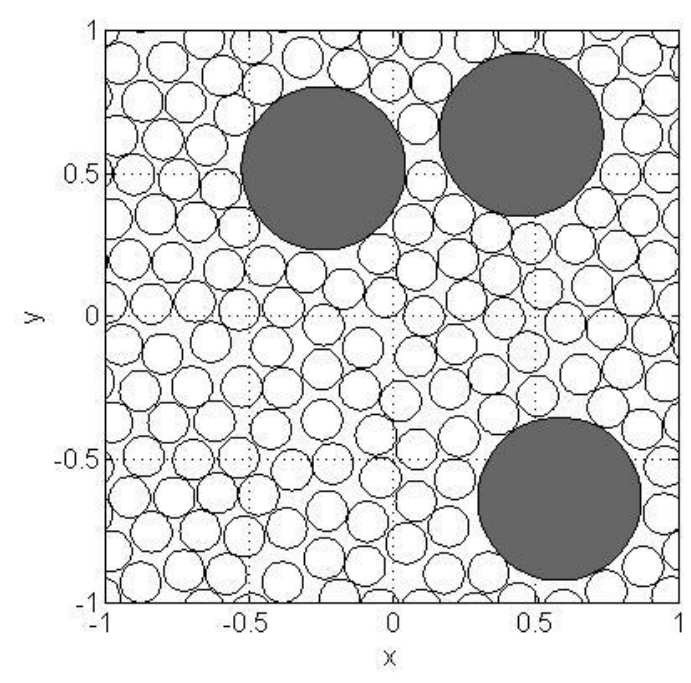

(a) Microscale propellant

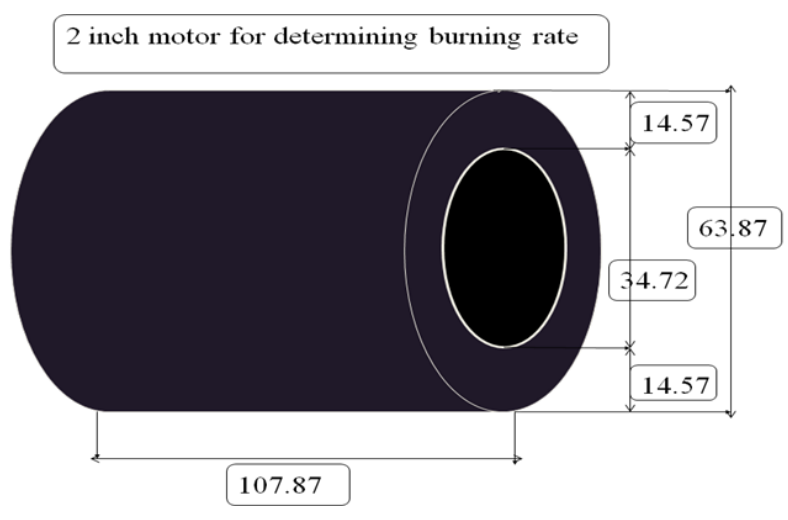

(b) two-inch motor propellant

Fig. 2 The physical model.

\section{KINETICS, GAS AND SOLID PHASES, MOVING GAS/SOLID INTERFACE EQUATIONS}

\section{1) Two-Step Kinetic Equations}

The BDP model [6,7] identifies three kinds of flames, but it has long been argued that the "primary diffusion flame," in which AP and binder gases react, is not important. The two survivors are the AP decomposition flame and the final diffusion flame in which the AP decomposition products react with binder gases; these two flames are part of the twodimensional model discussed here. The two-step kinetics that include the AP decomposition flame and the final diffusion flame is examined in order to achieve a good understanding of the unsteady burning of periodic 2D disk pack propellant with complete coupling between the solid and gas phases. 
It is useful to summarize the formulation of the constant density model[12,13] before addressing the complete problem, as this enable us to introduce most of the model ingredients together with various convenient scaling in the context of a model set of equations. The specific details of the constant density model for our problem are as follows: the density is set equal to constant (so that the equation of state, Charles law, is jettisoned); and a uniform velocity field $\mathrm{u}=0$ and $\mathrm{v}(\mathrm{y})=$ constant is adopted, which satisfies both the continuity and momentum equations. Thus; for two-step chemical kinetics:-

$A P(X) \stackrel{R_{1}}{\rightarrow}$ decompositionproducts $(z)$

$Z+\operatorname{binder}(y) \stackrel{R_{2}}{\rightarrow}$ finalproducts

$\mathrm{R}_{1}$ and $\mathrm{R}_{2}$ are assumed to have the forms;

$\mathrm{R}_{1}=\mathrm{B}_{1} \mathrm{P} X \exp \left(-\mathrm{E}_{1} / \mathrm{R}_{\mathrm{u}} \mathrm{T}\right)$ and

$\mathrm{R}_{2}=\mathrm{B}_{2} \mathrm{P}^{\text {ng }} \mathrm{Y} Z \exp \left(-\mathrm{E}_{2} / \mathrm{R}_{\mathrm{u}} \mathrm{T}\right)$,

Where B's are the exponential prefatory, E's are the activation energy in the gas phase, $\mathrm{P}$ is the pressure, $\mathrm{R}_{\mathrm{u}}$ is the universal gas constant, and ( $\mathrm{T}, \mathrm{X}, \mathrm{Y}$ and $\mathrm{Z}$ ) are the temperature, oxidizer, fuel and the decomposition products respectively.

\subsection{Gas Phase Equations}

The corresponding gas phase equations are;

$\rho_{g} \frac{D \phi}{D t}=\vec{\nabla}\left(\frac{\lambda_{g}}{C_{p}} \vec{\nabla} \phi\right)+\Psi$

Where;

$\phi=\left[\begin{array}{llll}T & X & Y & Z\end{array}\right]^{T}$,

$\Psi=\left[\begin{array}{llll}\left(Q_{g 1} R_{1}+Q_{g 2} R_{2}\right) / c_{p} & -R_{1} & -R_{2} & R_{1}-\beta R_{2}\end{array}\right]^{T}$

Lewis number is taken to be unity, then;

$\rho_{g} D_{g}=\lambda_{g} / c_{p}$

With the aid of the equation of state;

$$
P=\rho R T
$$

Where $\beta$ is the stoichiometric ratio. Here there are six unknowns in the gas-phase, $(\mathrm{u}, \mathrm{v}, \mathrm{T}, \mathrm{X}, \mathrm{Y}, \mathrm{Z})$ and one unknown in the solid-phase $\left(\mathrm{T}_{\mathrm{s}}\right)$.

\subsection{Solid-Phase and Solid/Gas Interface Equations}

In the solid-phase, the following heat equation is used;

$$
\rho_{s} T_{t}=\frac{\lambda_{s}}{c_{p}} \nabla^{2} T
$$

Here, $\rho_{\mathrm{s}}$ is the density of the solid, T the temperature, and $\lambda_{\mathrm{s}}$ is the solid thermal conductivity. The specific heat $c_{p}$ is assumed to be equal to that in the gas phase for simplicity. The possibility of differing densities and thermal properties in the solid phase is allowed and setting by;
$\rho_{s}=\left\{\begin{array}{l}\rho_{A P} \\ \rho_{B}\end{array} \quad \lambda_{s}= \begin{cases}\lambda_{A P} & \psi \geq 0 \\ \lambda_{B} & \psi<0\end{cases}\right.$

The function $\psi(\mathrm{x}, \mathrm{y})$ is a level set function which demarks the regions of AP from binder (B) within the solid, so that a point $(\mathrm{x}, \mathrm{y})$ lies in the AP if $\psi(\mathrm{x}, \mathrm{y}) \geq 0$, and in the binder if $\psi(\mathrm{x}, \mathrm{y})<0$. Suppose the solid/gas interface defined by $\eta(\mathrm{x}(\mathrm{t}), \mathrm{y}(\mathrm{t}), \mathrm{t})=0$. Then;

$\eta_{t}+\eta_{x} \frac{d x}{d t}+\eta_{y} \frac{d y}{d t}=0$

And the final equation that control the moving of the gas/solid interface derived by Hegab, [23-25] and may be written as follows;

$\eta_{t}-r_{b}|\vec{\nabla} \eta|=0$

Where $r_{b}$ is defined as the speed of the front which moves in the directions of the solid. In general $r_{b}$ is given by the following simple pyrolysis law;

$r_{b}= \begin{cases}r_{A P}=A_{A P}\left(P / P_{0}\right)^{n_{A P}} \exp \left\{-E_{A P} / R_{u} T_{A P, s}\right\} & \psi \geq 0 \\ r_{B}=A_{B}\left(P / P_{0}\right)^{n_{B}} \exp \left\{-E_{B} / R_{u} T_{B, s}\right\} & \psi<0\end{cases}$

Note that pressure dependence has been added to the pyrolysis law for generality.

In the study, the propellant surface is not flat and its shape changes with time. Therefore, the following mapping function is used;

$\eta=\mathrm{y}-\mathrm{f}(\mathrm{x}, \mathrm{t})$

And the front of equation (10) reduces to the simple Hamilton-Jacobi equation;

$f_{t}+r_{b}(x, t) \sqrt{1+f_{x}^{2}}=0$

\subsection{Boundary/Jump Conditions}

The appropriate jump conditions $[\phi]$ across the gas /solid interface are;

$\left[\rho\left(\vec{v} \cdot \vec{n}+r_{b}\right)\right]=0$

$[T]=0$

$[\lambda \vec{n} . \nabla T]=-Q_{s} m$

$m\left[\chi_{i}\right]=\left[\rho D \vec{n} . \nabla \chi_{i}\right], \quad i=1,2,3$,

Where $[\phi]=\phi_{\mathrm{g}}-\phi_{\mathrm{s}}$ denotes the jump in the quantity $\phi$ across the interface, $\chi_{i}$ refers to $\mathrm{X}, \mathrm{Y}$, and $\mathrm{Z}, \mathrm{m}$ is the mass flux. $\vec{n}$ is the unit normal pointing in the direction of the gas; $\vec{n}=\nabla \eta /|\nabla \eta|$, Fig. (3). $\mathrm{Q}_{\mathrm{s}}$ is the solid phase heat release term defined by

$$
Q_{s}= \begin{cases}Q_{A P} & \psi \geq 0 \\ Q_{b} & \psi \leq 0\end{cases}
$$

For an exothermic surface reaction, $\mathrm{Q}_{\mathrm{s}}>0$, and for an endothermic reaction, $\mathrm{Q}_{\mathrm{s}}<0$. Typically the AP is considered an exothermic reaction, while the binder is an endothermic one. The recent study by Hegab, [23-25] proved that the length and time scales for the front and the solid are the same order of magnitudes. 
On the other side, the ratio of the gas to solid or the ratio of the gas to front are of the order of $10^{-3}$. Thus for the present purpose, the quasi-steady approximation for the gas phase is employed. Note that disturbances with time scales of order $10^{-3} \mathrm{~s}$ would effect the solid phase, but not the gas phase; changes on time scales of order $10^{-5} \mathrm{~s}$ are needed to generate an unsteady gas phase and changes of this nature have been discussed in $[12,13]$.

\section{NUMERICAL SOLUTION TO HAMILTON- JACOBI EQUATION}

The surface equation (13) is solved in order to follow the non-planar regression surface by the first order temporal scheme $[12,13,23,25]$;

$$
f_{i}^{n+1}=f_{i}^{n} \Delta t \phi\left(\frac{f_{i}^{n}-f_{i-1}^{n}}{\Delta x}, \frac{f_{i+1}^{n}-f_{i}^{n}}{\Delta x}\right)
$$

Where $\varphi$ is a numerical flux function, Here, i denotes the discrete grid location $x_{i}, n$ the previous time level, and $n+1$ the new time level. Although there are many choices, the second-order Lax-Freidricks monotonic flux function is used;

$\phi_{L F}\left(u_{1}, u_{2}\right)=\frac{1}{2}\left(\frac{r_{b, i}+r_{b, i-1}}{2} \sqrt{1+u_{1}^{2}}+\frac{r_{b, i+1}+r_{b, i}}{2} \sqrt{1+u_{2}^{2}}\right)$

And $r_{b, i}$ is the local burn rate determined from the pyrolysis law. The CFL condition $\Delta \mathrm{t} \leq \mathrm{CFL}^{*} \Delta \mathrm{x}$ is satisfied for stability. Typically one would set $\mathrm{CFL}=$ $\left(\max \left\{r_{b}\right\}\right)^{-1}$; however the value of $1 / 4$ seems satisfactory.

Besides the non-flat regression surface mapping as in (11), another transformation is applied for the cluster grid points in regions adjacent to the wall, where most of the flow parameters changes rapidly. The solution of the final mapped equations is advanced in the solid phase using physical time (t). Simultaneously the solution in the gas phase using pseudo-time $(\tau)$ to the local steady state at the first physical time step (t) is advanced. The boundary/jump conditions are continually updated as. Then the Hamilton-Jacobi Eqn. (13) is advanced at the physical time by a third order ENO and a fifthorder WENO (weighted essentially non-oscillatory) solver. All numerical calculations were performed on a $140 \times 70$ grid, uniform in the $\mathrm{x}$-direction and stretched in the y-direction. The code in the gas phase is stopped between each two physical times when the relative difference between solutions at two different pseudo-time values is less than some prescribed tolerance, taken here to be $10^{-6}$. N Convergence tests were carried out and it was determined that any further refinement resulted in less than $1 \%$ relative error. Thermophysical properties of the gas, AP, and Binder are fitted to the following experimental data.

\section{EXPERIMENTAL WORK FOR THE MICROSCALE PROPELLANT}

The AP particle sizes are very small and vary between 5 to 500 microns. As a results the first model is employed to examine tiny packed samples to use it as a base of the two-inch motor.

\subsection{Experimental AP packing strategy}

The experiments are carried out using the vibration device for the AP particles. The setup is able to vibrate in three directions with different amplitudes and frequencies. The experimental procedure is as follows.

The raw materials selected for investigation were ammonium perchlorate powders $\left(\mathrm{NH}_{4} \mathrm{ClO}_{4}\right)$ with mean particle diameter of $10-500 \mu \mathrm{m}$, with density $1.95 \mathrm{~g} / \mathrm{cm}^{3}$, Molecular weight 117.49 and

Melting point, $315\left({ }^{\circ} \mathrm{C}\right)$. The experimental packing procedures are performed as follows;

1- Dry AP powder in vacuum oven for $24 \mathrm{hrs}$ at $80{ }^{\circ} \mathrm{C}$.

2- Adjust the conditions of lab environment to be humidity $<30 \%$ and temperature $<30{ }^{\circ} \mathrm{C}$.

3- Sieve AP powder by sieving analysis for 20 min.

4- Take each particle size individually after sieving then put in a pot, and finally, we get six different particle sizes.

5- Pack particles of mean particle size $187.5 \&$ $107.5 \& 76.5 \& 47.5 \& 10$ with the large one 375 , see table (1).

6- The containers of volume $13.5 \mathrm{ml}$ are cleaned using distilled water, dried in an oven at $60{ }^{\circ} \mathrm{C}$ and cooled down to room temperature.

7- The container was then fixed in the vibration device and the particles were poured down gently into the container to form the initial packing.

8- The setup is able to vibrate in three directions with different amplitudes.

9- The packing was then vibrated under a given condition for a period of time and stopped and the packing density was re-determined

Table (1) : Packed meshes

\begin{tabular}{|c|c|c|c|}
\hline \multirow{2}{*}{ Mesh } & \multirow{2}{*}{ micron } & \multicolumn{2}{|c|}{ Average } \\
\cline { 3 - 4 } & & mesh & micron \\
\hline $60-35$ & $250-500$ & 45 & 375 \\
\hline $120-60$ & $125-250$ & 90 & 187.5 \\
\hline $170-120$ & $90-125$ & 145 & 107.5 \\
\hline $230-170$ & $63-90$ & 200 & 76.5 \\
\hline $400-230$ & $32-63$ & 315 & 47.5 \\
\hline 1250 & $7-11$ & 1250 & 10 \\
\hline
\end{tabular}

The packing density is defined by the volume of the AP divided by the volume of the tube. The packing density of small spheres, in a mixture of large and small spheres, has been deduced by consideration of 
the extent of packing distortion brought about by the presence of large spheres. This is found to depend upon the proportion, size ratio and packing densities of the components.

As the size ratio increases, the form of the theoretical curve of packing density of a perfect real mixture plotted against the proportion of large particles, shows a flat region and a shift of its maximum to lower value of this proportion.

The packing density, however, is lower when the size ratio of coarse particles to fine particles decreases. A high maximum packing density is directly dependent upon the particle size distribution. Many studies have demonstrated the importance of the particle size distribution to obtain dense packing. For a two component mixture of coarse and fine particles, the ideal packing density is predicted to be about 0.86 at $70 \%$ coarse and $30 \%$ fine.

\subsection{Preparation of polyurethane sample based on HTPB}

Polyurethane sample is prepared using HTPB instead of GAP with the same procedure. The mechanical properties of sample was measured in order to compare with that sample based on GAP, Table (2) shows the formulation of this sample.

Table (2): Polyurethane sample formulation

\begin{tabular}{|c|l|l|}
\hline $\begin{array}{l}\text { Material } \\
\text { Name }\end{array}$ & Function & Wt., (gm) \\
\hline HTPB & $\begin{array}{l}\text { Inert } \\
\text { Prepolymer }\end{array}$ & 60.5 \\
\hline HMDI & Disocyanate & 5.5 \\
\hline DOZ & Plasticizer & 22.0 \\
\hline MAT & $\begin{array}{l}\text { Bonding } \\
\text { Agent }\end{array}$ & 2.0 \\
\hline \multicolumn{2}{|l|}{ Total Weight, $(\mathrm{gm})$} & 90.0 \\
\hline
\end{tabular}

\subsection{Preparation techniques of CSRP samples}

\subsubsection{Mixing the ingredients}

The mixing operation starts by placing GAP as a diol into a $500 \mathrm{ml}$ beaker, then $2 / 3$ of DOZ, MAPO and Al were added, and the whole mixture was mixed using a heavy duty mechanical mixer for about 30 min under constant temperature of $40^{\circ} \mathrm{C}$. After complete mixing of ingredients, the calculated amount of AP was added into 3 equal doses with continuous mixing, then the desired content of HMDI with the remaining $1 / 3$ of $\mathrm{DOZ}$ were added to the mixture and the whole contents were stirred for 15 $\min$, and the temperature was kept constant at $40^{\circ} \mathrm{C}$.

\subsubsection{Degassing operation}

The purpose of degassing operation was to remove the air bubbles to produce non-porous CSRP samples. After the final mixing of the samples, they were degasified using the degassing unit.

\subsubsection{Casting process}

The degasified CSRP samples were carefully casted in dumbbell shape standard die (JANNAF), then the sample mould and pressed by a spatula to insure the absence of any empty spaces inside the mould.

\subsubsection{Curing process}

The moulds are put in an oven under a temperature of $60^{\circ} \mathrm{C}$ for $10-14$ days, and then we carefully get the propellant samples out of the moulds. More details about these processes will be published in somewhere else.

\section{RESULTS AND DISCUSIONS}

The understanding of the complex combustion structure of the AP/HTPB propellant, as a simple model to the heterogeneous solid rocket propellant, is studied using the experimental and theoretical approaches. The theoretical packing strategy described the disk pack model by assuming that the particles of the AP are 2D disks and distributing them in a random fashion and applied to a binary packs, distributions of disks with different sizes. We start with a periodic arrays of 2D discs, and in one of these discs, an $\mathrm{N}$ points are randomly placed, each of which is randomly assigned a velocity. These points are kernels for the AP particles that will eventually pack the disc. As time advanced each kernel will grow with a certain growth rate and move randomly through the packing process.

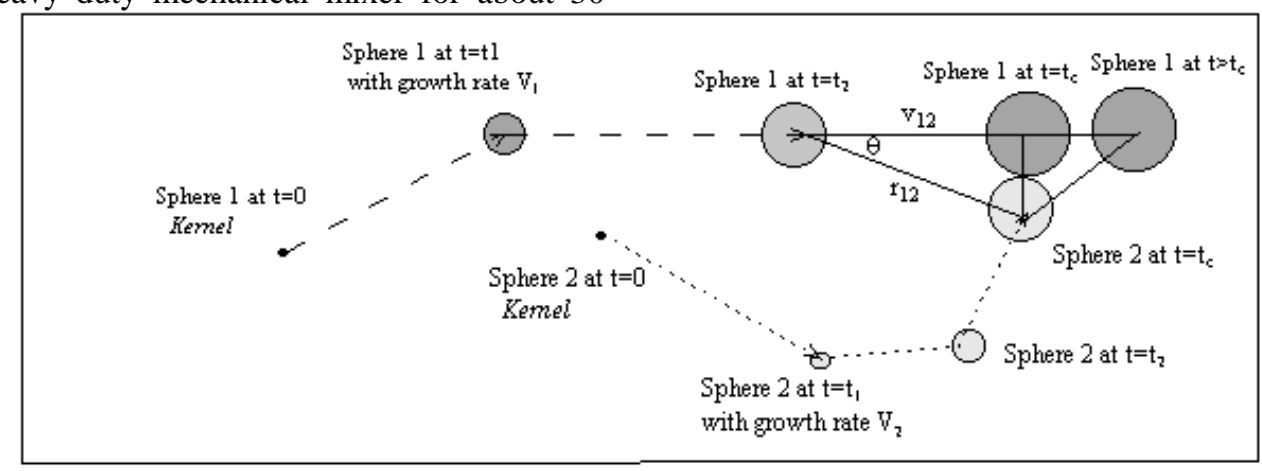

Fig. 3 Moving and growing of two spheres 1 and 2 from zero time to the first collision time $\left(t_{c}\right.$ 
If two particles collide as shown in figure 3 before the final packing is achieved, an additional centerline force is given to make them move and continue growing until the final packing density is satisfied. In addition, the $2 \mathrm{D}$ combustion field supported by a disk pack propellant, in which full coupling between the gas phase, the condensed phase, and the retreating nonplanar propellant surface is accounted for.

Figure 4 shows the position of the combustion surface at various times, equally spaced, during the consumption of a single square (randomly packed) of a periodic pack. They added also some insight into the nature of the combustion field supported by such a propellant as in Fig. 5.

Moreover, the morphology of the burning rate adjacent to the combustion surface is presented in Fig. 6. This figure shows how the burning rate attains maximum values through the burning of the large AP particles that found between $-3<\mathrm{x}<0$, and $.8<\mathrm{x}>$ 4.5 .

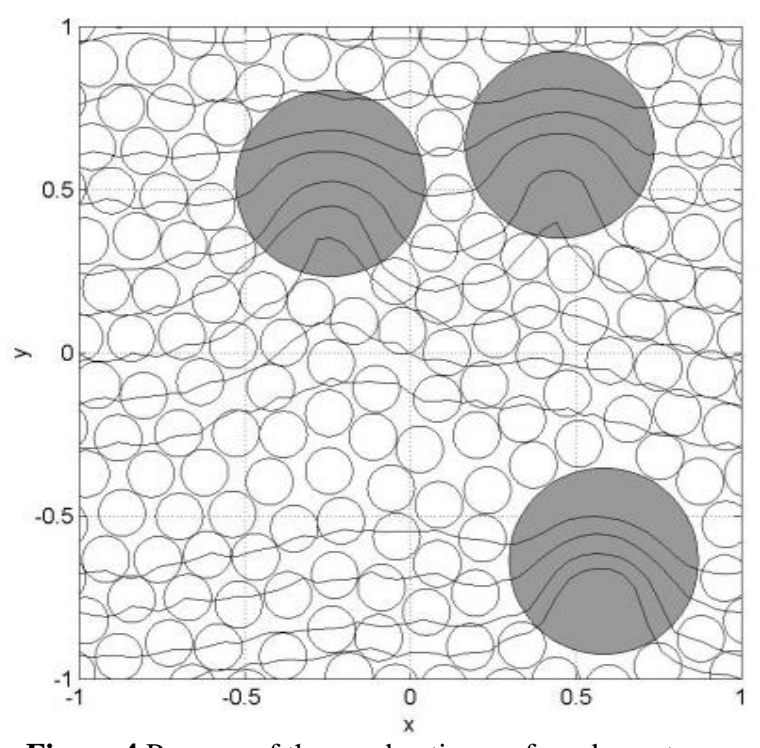

Figure 4 Passage of the combustion surface downstream through a disc pack in Fig. 2.
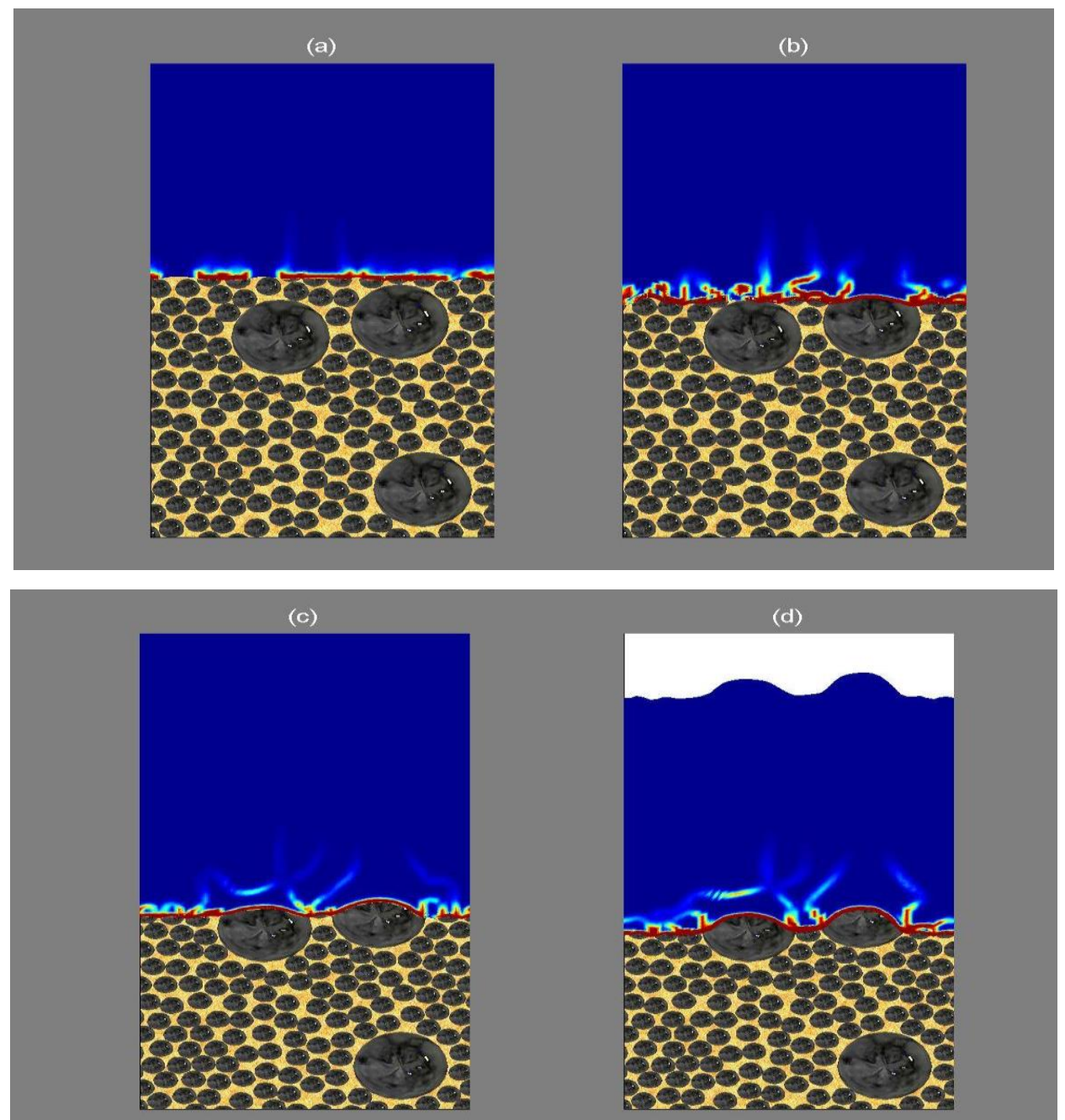

Fig. 5 Reaction rate contours above a burning "bimodal" disk-pack at different times a) $t=0.2, b$ ) $t=0.4$, c) $t=0.6$, and d) $t=0.6$. 
Hegab, A.M., Hasanien, S.A., Mostafa, H. E., Maraden, A.M, "Experimental and Numerical Investigations ..."

Table (3) Packing fractions for the whole packed samples

\begin{tabular}{|c|c|c|c|c|c|c|}
\hline \multicolumn{2}{|c|}{ Codes } & \multirow{2}{*}{ 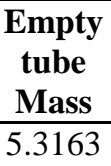 } & \multirow{2}{*}{$\begin{array}{c}\begin{array}{c}\text { Filled tube } \\
\text { Mass }\end{array} \\
22.4498 \\
\end{array}$} & \multirow{2}{*}{$\begin{array}{c}\begin{array}{c}\text { APc } \\
\text { Mass }\end{array} \\
17.1335\end{array}$} & \multirow{2}{*}{$\begin{array}{c}\begin{array}{c}\text { APc } \\
\text { Volume }\end{array} \\
8.7864\end{array}$} & \multirow{2}{*}{$\begin{array}{c}\text { Packing } \\
\text { Fraction } \\
0.6461\end{array}$} \\
\hline & $X$ & & & & & \\
\hline & B & 5.4058 & 22.4364 & 17.0306 & 8.7336 & 0.6422 \\
\hline & $\mathrm{N}$ & 5.5133 & 22.4615 & 16.9482 & 8.6914 & 0.6391 \\
\hline & $Y$ & 5.6074 & 22.5683 & 16.9609 & 8.6979 & 0.6396 \\
\hline & $\mathrm{Z}$ & 5.4951 & 22.4439 & 16.9488 & 8.6917 & 0.6391 \\
\hline & $\mathrm{A}$ & 5.5148 & 22.4303 & 16.9155 & 8.6746 & 0.6378 \\
\hline \multirow{6}{*}{ 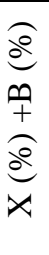 } & X9B1 & 5.3163 & 22.7657 & 17.4494 & 8.9484 & 0.6628 \\
\hline & X7B3 & 5.4058 & 23.2696 & 17.8638 & 9.1609 & 0.6786 \\
\hline & X5B5 & 5.5133 & 23.2575 & 17.7442 & 9.0996 & 0.6740 \\
\hline & X3B7 & 5.6074 & 23.3999 & 17.7925 & 9.1244 & 0.6759 \\
\hline & X2B8 & 5.4951 & 22.8824 & 17.3873 & 8.9166 & 0.6605 \\
\hline & X1B9 & 5.5148 & 22.6457 & 17.1309 & 8.7851 & 0.6507 \\
\hline \multirow{6}{*}{ 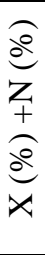 } & X9N1 & 5.5116 & 23.5486 & 18.0370 & 9.2497 & 0.6852 \\
\hline & X7N3 & 5.3882 & 24.2588 & 18.8706 & 9.6772 & 0.7168 \\
\hline & X5N5 & 5.5125 & 23.6744 & 18.1619 & 9.3138 & 0.6899 \\
\hline & X3N7 & 5.3841 & 23.2512 & 17.8671 & 9.1626 & 0.6787 \\
\hline & X2N8 & 5.5269 & 22.9839 & 17.4570 & 8.9523 & 0.6631 \\
\hline & X1N9 & 5.4047 & 22.6704 & 17.2657 & 8.8542 & 0.6559 \\
\hline \multirow{6}{*}{$\begin{array}{l}\frac{8}{2} \\
\underbrace{+}_{x} \\
\frac{8}{x}\end{array}$} & X9Y1 & 5.4705 & 24.0491 & 18.5786 & 9.5275 & 0.7057 \\
\hline & $\mathrm{X} 7 \mathrm{Y} 3$ & 5.5079 & 25.7292 & 20.2213 & 10.3699 & 0.7681 \\
\hline & X5Y5 & 5.5079 & 25.2209 & 19.7130 & 10.1092 & 0.7488 \\
\hline & X3Y7 & 5.6287 & 24.4082 & 18.7795 & 9.6305 & 0.7134 \\
\hline & $\mathrm{X} 2 \mathrm{Y} 8$ & 5.6075 & 23.6435 & 18.0360 & 9.2492 & 0.6851 \\
\hline & X1Y9 & 5.5298 & 23.0442 & 17.5144 & 8.9817 & 0.6653 \\
\hline \multirow{6}{*}{$\frac{\underbrace{8}_{x}}{\underbrace{8}_{+}}$} & X9Z1 & 5.4047 & 24.3298 & 18.9251 & 9.7052 & 0.7189 \\
\hline & X7Z3 & 5.5116 & 26.3145 & 20.8029 & 10.6682 & 0.7902 \\
\hline & X5Z5 & 5.3882 & 25.8727 & 20.4845 & 10.5049 & 0.7781 \\
\hline & X3Z7 & 5.6074 & 24.1227 & 18.5153 & 9.4950 & 0.7033 \\
\hline & $\mathrm{X} 2 \mathrm{Z} 8$ & 5.3841 & 23.2627 & 17.8786 & 9.1685 & 0.6791 \\
\hline & X1Z9 & 5.5269 & 22.7441 & 17.2172 & 8.8293 & 0.6540 \\
\hline \multirow{6}{*}{ 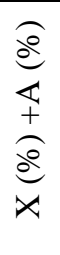 } & X9A1 & 5.4705 & 24.5172 & 19.0467 & 9.7675 & 0.7235 \\
\hline & X7A3 & 5.5079 & 27.0859 & 21.5780 & 11.0656 & 0.8197 \\
\hline & X5A5 & 5.5079 & 26.0158 & 20.5079 & 10.5169 & 0.7790 \\
\hline & X3A7 & 5.4951 & 24.5205 & 19.0254 & 9.7566 & 0.7227 \\
\hline & $\mathrm{X} 2 \mathrm{~A} 8$ & 5.6075 & 23.7554 & 18.1479 & 9.3066 & 0.6894 \\
\hline & X1A9 & 5.5298 & 22.9152 & 17.3854 & 8.9156 & 0.6604 \\
\hline
\end{tabular}

Where the code name matches the mesh numbers

\begin{tabular}{|ccccccc|}
\hline$(\mu \mathrm{m})$ & $250-500$ & $125-250$ & $90-125$ & $63-90$ & $32-63$ & $7-11$ \\
$\begin{array}{c}\text { Mesh } \\
\text { Number } \\
\text { Code }\end{array}$ & 45 & 80 & 140 & 200 & 300 & 1250 \\
& $\mathrm{X}$ & $\mathrm{B}$ & $\mathrm{N}$ & $\mathrm{Y}$ & $\mathrm{Z}$ & $\mathrm{A}$ \\
\hline
\end{tabular}




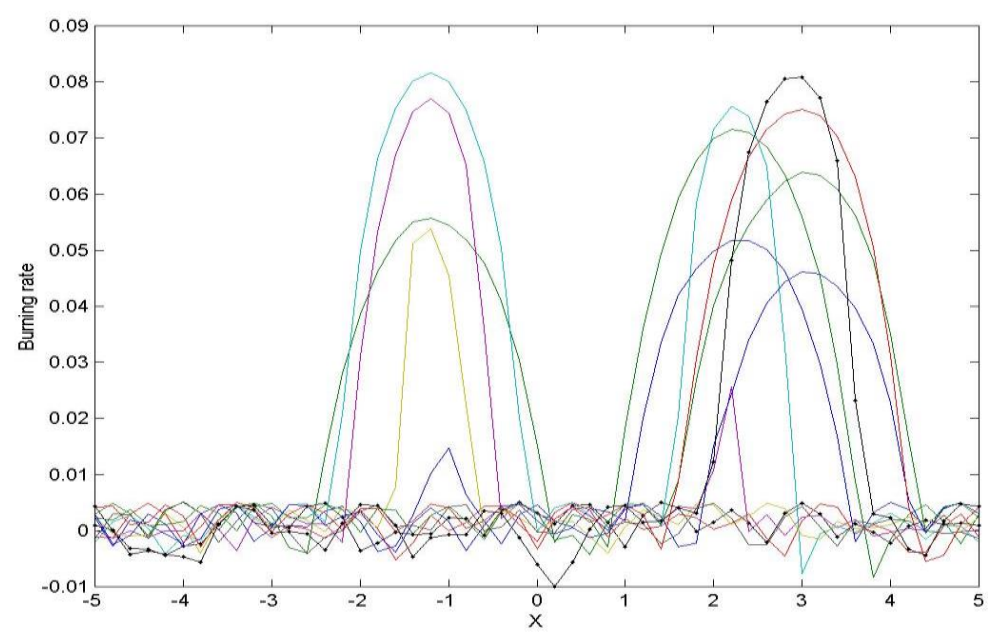

Fig. 6 Axial variation of the burning rate adjacent to the combustion surface at different times

The second set of the results is directed to the experimental packing of the AP with different sizes, as shown in table (3). The packing density of small spheres, in a mixture of large and small spheres, has been deduced by consideration of the extent of packing distortion brought about by the presence of large spheres. This is found to depend upon the proportion, size ratio and packing densities of the components.

As the size ratio increases, the form of the theoretical curve of packing density of a perfect real mixture plotted against the proportion of large particles, shows a flat region and a shift of its maximum to lower value of this proportion, see Fig. 7. The packing density, however, decreases as the size ratio of coarse particles to fine particles decreases.

A high maximum packing density is directly dependent upon the particle size distribution. Many studies have demonstrated the importance of the particle size distribution to obtain dense packing. For a two component mixture of coarse and fine particles, the ideal packing density is predicted to be about 0.86 at $70 \%$ coarse and $30 \%$ fine.

Comparing the real experimental of AP's, in table (3), with the sphere shots by McGeary, [15] is found to be qualitatively similar. The above samples is used to establish a 2-inch rocket motor. The burning of these samples in table (3) and the pressure-time curve in a two-inch rocket motor, is performed.

Finally, the burning process of the combustion of AP/HTPB is influenced by the propellant compositions for the micoscale propellant and, in turn, reflect the behaviuor of the prototype rocket system for example the two-inch one. The result of these two models reveal the ability of the theoretical random packing process to match the experimental one and the flame structure over the combustion surface at any time are exist.

\section{CONCLUSION}

Here, random packing for bimodal (2 different grain size) is discussed also $2 \mathrm{D}$ calculations to the combustion of heterogeneous solid propellant, accounting for the gas phase physics, the solid phase physics and an unsteady non-planar description of the regressing propellant surface is developed. Moreover, experimental investigation for miroscale propellant and two-inch motor propellant is performed. There are a number of issues that have discussed. The speed within which the combustion surface recedes depends on the exposed pressure in the gas phase, the effect of propellant composition on the combustion and shape of the flame. In addition a variety of steady-state surface shapes are achieved.

It is clearly seen that the large AP particles act as a resistance in the way of the combustion process and, in turn, slow the burning speed of the combustion surface than that with the mixture of small particles imbedded in HTPB powder.

In general, the results of the two models described here are preliminary ones and will be used as a base for further investigations to study the effect of different packing samples on the stability and performance of the two inch motor propellant. Furthermore, more intensive computational work is needed to study the effects of cross-flow in solid rocket motor chamber on the burning rate of a real long scale multimodal composite propellant. More details about the experimental processes used in this study will be published in somewhere else.

\section{Acknowledgments}

Hegab A.M., would like to thank the Science and Technology Development Fund (STDF), Egypt through the project STDF-ID-108, and King Abdulaziz University, KSA for their support. 


\section{Packing Curve}

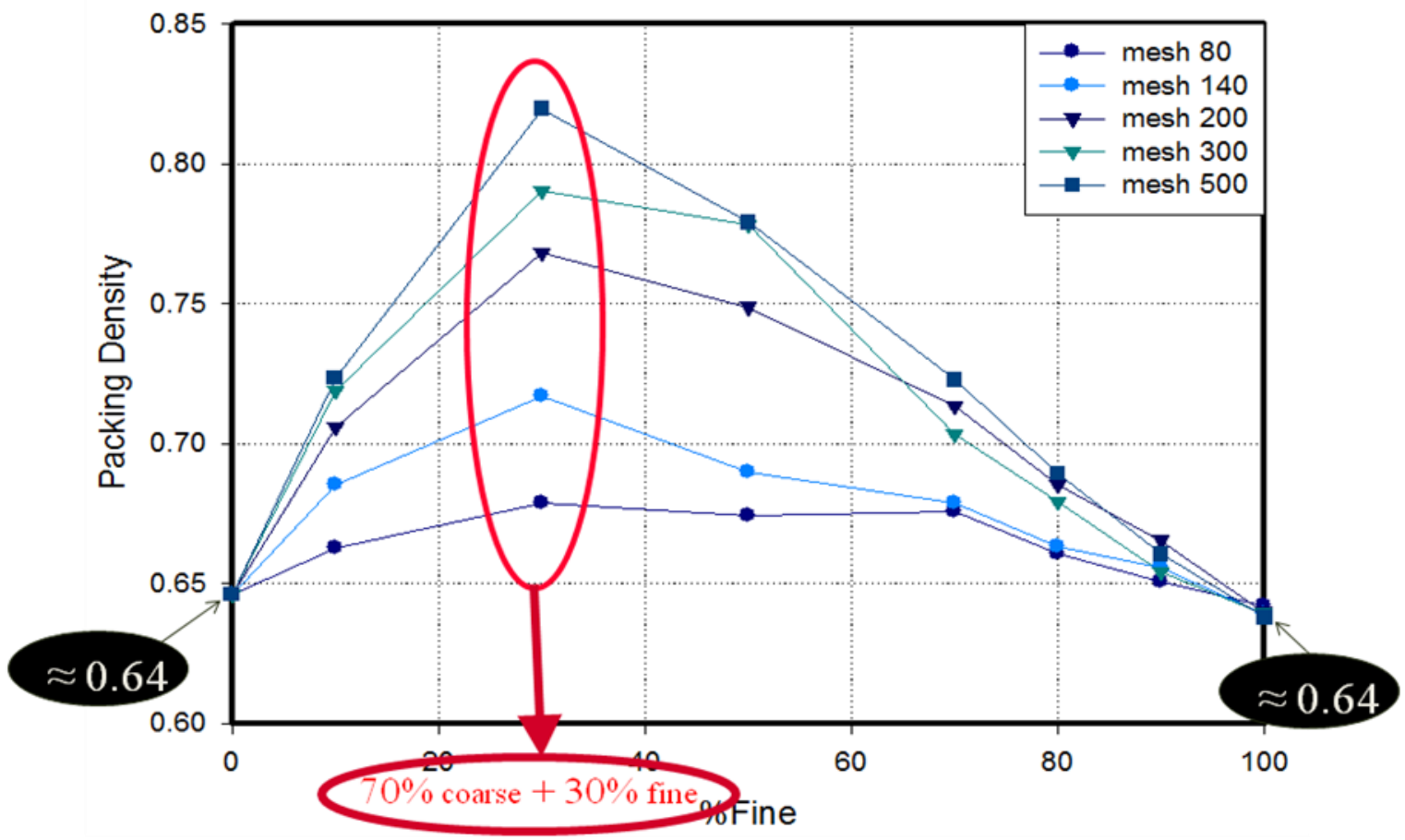

Fig. 7 Packing density vs. the fine mode percent for current experimental packing.

\section{REFERENCES}

[1] Ferreira, J.G., Bizoi, A, and Lengelle, G. "Model for Double-Base Propellants Combustion, without and with Additives", 19th AIAA/ASME/SAE Joint Propulsion Conference, AIAA Paper -83-1197, (1983).

[2] Wu, X., Kumar, M., and Kuo, K, "A Comprehesive Erosive-Burning Model for Double-Base Propellants in Strong Turbulent Shear Flow"; Combustion and Flame, Vol. 55, 49-63 (1983).

[3] Most, J., and Joulain, P., "Modeling of Normal and Erosive Burning Rate of a Hot Double-Base Homogeneous Propellant", Combustion and Flame, 105:202-210 (1996).

[4] Tseng, I.S. and Yang, V., "Combustion of a Double-Base Homogeneous Propellant in a Rocket Motor", Combustion and Flame 96:325342, (1994).

[5] Huggett, G, Bartley, C., and Mills, M., "Solid Propellant Rockets", Princeton University Press, 1960.

[6] Beckstead, M.W., Tanaka,M., Jing, Q., and Jeppson, M. B., "An Ammonium Perchlorate Model Based on a Detailed Mechanism," 33rd JANNAF Combustion Meeting, CPIA Publ. 638, Chemical Propulsion Information Agency, Laurel, MD, 1996, pp. 41-46.
[7] Jeppson, M. B., Beckstead, M. W., and Jing, Q., "A Kinetic Model for the Premixed Combustion of a Fine AP/HTPB Composite Propellant," 35th JANNAF Combustion Meeting, CPIA Publ. 680, Chemical Propulsion Information Agency, Laurel, MD, 1998, pp. 639-654.

[8] Guiro, C. and Williams, F. "A Model for Ammonium Perchlorate Deflagration between 20 and 100 atm" AIAA Journal, Vol. 9, No.7, July 1971.

[9] Jeppson, M. B., Beckstead, M. W., and Jing, Q., "A Kinetic Model for the Premixed Combustion of a Fine AP/HTPB Composite Propellant," 36th Aerospace Sciences and Exhibit, AIAA-980447, Jan. 12-15, 1998, Reno, NV.

[10] Ward, M., Son, S., Brewster, M. "Role of Gasand Condensed-Phase Kinetics in Burning rRate Control of Energetic Solids", Combustion Theory Modeling Vol.2, pp293-312, 1998.

[11] Ward, M., Son, S., Brewster, M. "Steady Deflagration of HMX with Simple Kinetics: A Gas Phase Chain Reaction Model" Combustion and Flame, 114:556-568 (1998).

[12] Hegab, A., Jackson, T., Buckmaster, J., and Stewart, S., "The Burning of Periodic Sandwich Propellants", 36th AIAA/ASME/SAE/ASEE Joint Propulsion Conference, AIAA Paper 20003459, (2000). 
[13] Hegab, A., Jackson, T., Buckmaster, J., and Stewart, S., "Nonsteady Burning of Sandwich Propellant with Complete Coupling between the Solid and Gas Phases" Combustion and Flame, Vol. 125(1/2), PP 1055-1070, (2001).

[14] Knott, G.M. and Brewster, M.Q., "TwoDimensional Combustion Modeling of Heterogeneous Propellants with finite Peclet Number", Combustion and Flame, Vol. 121(1/2), PP 91-106, (2000).

[15] McGeary, R. K., "Mechanical Packing of Spherical Particles," Journal of the American Ceramic Society, Vol. 44, No. 10, 1961, pp. 513-522.

[16] Kochevets, S., Buckmaster, J., and Jackson, T. L., "Random propellant packs and the flames they support", 36th AIAA/ASME/SAE/ASEE Joint Propulsion Conference. AIAA Paper 20003461, 2000.

[17] Kochevets, S., Buckmaster, J., and Jackson, T., and Hegab, A.,'Random Packs and their Use in Modeling Heterogeneous Solid Propellant Combustion", Journal of Propulsion \& Power Vol.17 No.4, pp. 883-891, July-Aug. 2001.

[18] Knott, G. M., Jackson, T. L., and Buckmaster, J., "The Random Packing of Heterogeneous Propellants," AIAA Journal, Vol. 39, No. 4, pp. 678- 686.

[19]Buckmaster, J., Jackson, T. L., Hegab, A., and Kochevets, S., "Modeling Propellants and
Modeling Propellant Flames," 37th JANNAF Combustion Meeting, 2000.

[20] Buckmaster J., Jackson T., Hegab A., Kochevets S., Ulrich M. "Randomly Packed Heterogeneous Propellants and the Flame They Support" AIAA paper 2001-0337, 39th. Aerospace Science Meeting, Reno, NV, 2001.

[21]Lubachevsky, B. D., and Stillinger, F. H., "Geometric Properties of Random Disk Packings," Journal of Statistical Physics, Vol. 60, Nos. 5/6,pp. 561-583, 1990.

[22] Lubachevsky, B. D., Stillinger, F. H., and Pinson, E. N., "Disks vs. Spheres: Contrasting Properties of Random Packings," Journal of Statistical Physics, Vol. 64, Nos. 3/4, pp. 501524, 1991.

[23] Hegab, A.M. (2003), "Modeling of Microscale Solid Propellant Combustion"; The Tenth International Conference on Aerospace Science \& Aviation Technology, ASAT-10, May 13-15, 2003, Cairo, Egypt.

[24] Hegab, A.M. (2003), "Combustion Modeling of Micro-Structure Solid Propellant";Engineering Research Journal ERJ, Minufiya University, Vol. 26, No.3, July 2003.

[25]Hegab, A.M. (2007), "Effect of ammonium perchlorate grain size on combustion of a selected composite solid propellant"; The 12th International Conference on Aerospace Science \& Aviation Technology, ASAT-12, May 2007, Cairo, Egypt. 